\title{
The profile of deliberate self-poisoning cases presenting at the emergency department of Pelonomi Regional Hospital, Bloemfontein
}

\author{
MOA Benedict ${ }^{a}$ (D, CJ van Loggerenberg ${ }^{b}$ and WJ Steinberg ${ }^{a *}(\mathbb{C}$ \\ ${ }^{a}$ Department of Family Medicine, University of the Free State, Bloemfontein, South Africa \\ ${ }^{b}$ Department of Family Medicine, University of the Witwatersrand, Johannesburg, \\ South Africa \\ *Corresponding author, email: steinbergwj@ufs.ac.za
}

Background: A common method engaged in suicide is deliberate self-poisoning (DSP). Substances implicated in DSP include prescription and over-the-counter medicines, drugs, household chemicals, agrochemicals and herbal mixtures. Few studies have been conducted on DSP in South Africa, despite its occurrence and high management cost. This study aimed to determine the profile of patients treated for DSP at the emergency department of Pelonomi Regional Hospital, Bloemfontein, between January 2010 and July 2011. A profile of DSP cases will allow practitioners in this region to be aware of the magnitude, causes and common substances used, which will enable them to plan and execute an adequate management protocol to reduce mortality.

Methods: This was a retrospective, descriptive study. All DSP patients treated during the 18-month study period were identified from the emergency department register. The clinical files of these patients were reviewed and relevant information captured. Results: In total, 260 DSP patients presented at the emergency department. Files for 212 (81.5\%) patients had sufficient information and were included in the study. Two-thirds $(66.0 \%, n=140)$ of the patients were female and the highest percentage was in the age group 20-29 years $(44.8 \%, n=94)$. Most patients were black $(81.1 \%, n=150)$. Most resided in areas associated with low socioeconomic status, including informal settlements, farms and townships. The highest percentage of patients took paracetamol $(21.7 \%, n=46)$, while $19.3 \%(n=41)$ ingested household chemicals and $9.9 \%$ $(n=21)$ antiretroviral medication. Only 81 of the 212 patient files had the reason for the DSP captured. Of these, half $(49.4 \%)$ reported troubled relationships.

Conclusion: This study showed that DSP mostly occurred among females in the age group 20-29 years. Most of the patients resided in areas with poor socioeconomic status, and faced relationship, marital, employment and other psychosocioeconomic problems.

Keywords: emergency service, parasuicide, poisoning, self-injurious behaviour, suicide

\section{Introduction}

Suicide is a worldwide phenomenon resulting in the deaths of more than 800000 people each year. ${ }^{1}$ In 2012 , suicide was reported to be the leading cause of death among $15-$ to $29-$ year-olds. ${ }^{1}$ Up to 8000 South Africans commit suicide annually, accounting for $10 \%$ of all unnatural deaths in adults and $9.5 \%$ of unnatural deaths in youths. ${ }^{2}$ According to the South African Depression and Anxiety Group (SADAG) in 2014, an estimated 23 suicides and 230 attempted suicides take place daily and nearly two-thirds of victims are between 20 and 39 years of age. ${ }^{1}$

One of the methods engaged in suicide is deliberate self-poisoning (DSP). Common substances implicated in DSP include prescription and over-the-counter medication, drugs of abuse, household chemicals, agrochemicals and herbal mixtures. ${ }^{3}$ Deliberate self-poisoning, when it is nonfatal, and particularly when it is grouped with self-injury, is also called 'deliberate self-harm', 'attempted suicide' or 'parasuicide', ${ }^{4,5}$ The World Health Organization defines this as 'an act with a nonfatal outcome in which an individual deliberately ingests a substance in excess of the prescribed or generally recognized therapeutic dosage'. ${ }^{6}$ Deliberate self-poisoning is not just for the purpose of suicide; it is also employed to gain attention, express distress or to get revenge. ${ }^{7}$

Deliberate self-poisoning in developed countries has been associated with significant morbidity and mortality. ${ }^{8}$ Deliberate self-poisoning appears to be a major public health issue in developing countries as well. In rural Sri Lanka, DSP is one of the leading causes of hospital deaths. ${ }^{9}$ A study done in Uganda on acute poisoning showed an equal prevalence of DSP among males and females. ${ }^{10}$ Another study showed a significant use of pesticide for DSP in Uganda, Kenya, Nigeria, Zimbabwe and Ethiopia. ${ }^{11}$ The choice of drugs or poison for DSP varies between different countries in different stages of development, depending rather on the availability of the substance and not necessarily its lethality. ${ }^{8}$

Patients taking an overdose of drugs or poison, whether intentional or accidental, are often seen in emergency departments in South Africa. A subjective evaluation by doctors and nurses at a hospital in the Western Cape found a high incidence of patients who had overdosed presenting for treatment. ${ }^{12}$ This study showed that the overdosing occurred commonly among black females of childbearing age, belonging to the working class and residing in areas with greater likelihood for psychosocioeconomic problems.

Another study on deliberate self-harm done in KwaZulu-Natal showed that most patients were young, single African women with at least secondary-level education. ${ }^{13}$ Most $(78 \%)$ of the admissions were for parasuicide, with relational issues contributing to more than $50 \%$ of cases and circumstance challenges 
contributing to about $30 \%$. In a study carried out among attempted suicide cases referred for psychological assessment and treatment at Pelonomi Regional Hospital in Bloemfontein, self-poisoning accounted for $90.7 \%$ of the cases, the majority of whom were females. ${ }^{5}$ In Bloemfontein, $16.2 \%$ of the suicide cases investigated in the state mortuary were due to DSP. ${ }^{2}$

More studies should be conducted on this subject in South Africa, owing to its common occurrence and the high cost required in its management. ${ }^{12,14,15} \mathrm{~A}$ study on self-poisoning by pesticide has shown that most patients reach the hospital alive ${ }^{7}$-the survival of such patients, therefore, to a large extent depends on the competence of the attending doctors and other health professionals in the emergency department. Thus, inadequate research into DSP may lead to poor knowledge of health professionals on the approach to victims of DSP and this may result in a poor outcome. ${ }^{7}$ Good knowledge and awareness of health professionals on the common substances used for poisoning in their locality, and the usual clinical features and outcome, through clinical research will incite them into acquiring proper diagnostic and management skills, thereby preventing unnecessary complications and death. ${ }^{9}$

\section{Aim of the study}

The aim of this study was to determine the profile of patients treated for deliberate self-poisoning at the emergency department of Pelonomi Regional Hospital between January 2010 and July 2011.

Objectives were to determine the (i) demographic details, (ii) reasons for and circumstances surrounding the DSP, (iii) drug or poison ingested, and (iv) clinical state and outcome of the patients.

\section{Methods}

\section{Study design, target population and sampling}

This was a retrospective, descriptive study. The target population included all DSP patients who presented at Pelonomi Regional Hospital emergency department for treatment between January 1, 2010 and June 30, 2011.

Pelonomi Regional Hospital is situated in Bloemfontein, Free State province, and is the referral centre for patients from neighbouring district and regional hospitals. The hospital currently serves an estimated 750000 people. The emergency department serves as the entry point (for initial/emergency treatment and resuscitation) for some medical and surgical emergency cases, which eventually are transferred to the appropriate departments for definitive management.

\section{Data collection}

All DSP patients presenting for treatment during the 18-month study period were identified from the emergency department patient register. The clinical files of these patients were reviewed and relevant information recorded on a data collection form, compiled by the first author based on DSP trends observed in similar studies examined.

Demographic details captured included gender, age group, ethnic group, occupation, marital status and residential area. Information pertaining to the DSP event included date, main type of drugs and/or poison ingested, number $(2,3$ or $>3)$ of drugs and/or poison ingested, concomitant alcohol and illegal drug use, main reason for DSP, previous attempts, and time interval between event and presentation to the emergency department. Clinical information included pre-hospital intervention, medical co-morbidities, clinical state on presentation to the emergency department, patient complications, and outcome (discharge, admission, death).

According to the clinical psychologist at National District Hospital in Bloemfontein (personal communication with Natasha Burgess, MA Clinical Psychology, May 3, 2012), the most common psychosocial-economic stressors implicated in patients with suicidal behaviours in Bloemfontein are marital and relationship disharmony, health concerns, family issues, depression and unemployment. For the purpose of this study, eight categories were set. The first author reviewed the clinical notes to ascertain the main reason for the patient's DSP attempt.

\section{Pilot study}

The data form was pre-tested on the first five patient files (in succession), to ensure that the questions were balanced, correctly constructed and that the crucial information would be obtained. No significant changes resulted from the pilot study, and the five patient files were included in the study.

\section{Data analysis}

Data were entered into an Excel spreadsheet (Microsoft Corp, Redmond, WA, USA) and analysed using the Statistical Package for the Social Sciences (SPSS, version 22; IBM Corp, Armonk, NY, USA). Results were summarised by descriptive statistics for continuous data and frequencies and percentages for categorical data.

\section{Ethical aspects}

The study was approved by the Ethics Committee of the Faculty of Health Sciences, University of the Witwatersrand (M120427). The Chief Executive Officer of Pelonomi Regional Hospital gave permission to conduct the study. No identifying information was captured on the data sheet and data were handled confidentially.

\section{Results}

In total, 260 DSP patients presented at the emergency department during the study period. Of these patients, files for 212 (81.5\%) patients had sufficient information and were included in the study. The remaining 48 patient files were either missing or incomplete and could not be analysed. Table 1 summarises the general demographic data of the study sample.

\section{Demographics of participants}

Two-thirds $(66.0 \%, n=140)$ of the patients were female and the highest percentage was in the age group $20-29$ years $(44.8 \%$, $n=94$ ). None of the patients were 60 years and older. The majority of the patients were black $(81.1 \%, n=150)$ whereas none of the patients were of Indian or Asian descent. However, the ethnicity of $12.7 \%(n=27)$ of the patients was not recorded. Patients were mostly unemployed $(65.6 \%, n=$ 139). Learners and students accounted for 19.3\% $(n=41)$ of the patients. Almost all of the patients were single, i.e. unmarried $(88.0 \%, n=184)$ and none were widowed. The majority of the patients resided in areas associated with low socioeconomic status, which include informal settlements, farms and townships.

\section{Frequency of DSP occurrence}

A high percentage of the DSP events occurred between February 2010 and April 2010 (Figure 1). The highest percentage of DSP events occurred on a Monday $(18.4 \%, n=39)$ and the lowest percentage on a Thursday $(9.0 \%, n=19)$. 
Table 1: General demographics of patients who were treated at Pelonomi Regional Hospital emergency department for deliberate self-poisoning

\begin{tabular}{|c|c|}
\hline Variable & $n(\%)$ \\
\hline \multicolumn{2}{|l|}{ Gender $(n=212)$ : } \\
\hline Male & $72(34.0)$ \\
\hline Female & $140(66.0)$ \\
\hline \multicolumn{2}{|l|}{ Age group (years) $(n=210)$ : } \\
\hline Under 16 & $6(2.9)$ \\
\hline $16-19$ & $38(18.1)$ \\
\hline $20-29$ & $94(44.8)$ \\
\hline $30-39$ & $51(24.3)$ \\
\hline $40-49$ & $14(6.7)$ \\
\hline $50-59$ & $7(3.3)$ \\
\hline \multicolumn{2}{|l|}{ Ethnic group $(n=185)$ : } \\
\hline Black & $150(81.1)$ \\
\hline White & $17(9.2)$ \\
\hline Coloured & $18(9.7)$ \\
\hline \multicolumn{2}{|l|}{ Occupation $(n=212)$ : } \\
\hline \multicolumn{2}{|l|}{ Scholar } \\
\hline Learners (primary or secondary school) & $24(11.3)$ \\
\hline Students (tertiary institution) & $17(8.0)$ \\
\hline \multicolumn{2}{|l|}{ Employment category } \\
\hline Employed by contract & $31(14.6)$ \\
\hline Self-employed & $1(0.5)$ \\
\hline Unemployed & $139(65.6)$ \\
\hline \multicolumn{2}{|l|}{ Marital status $(n=209)$ : } \\
\hline Single (unmarried) & $184(88.0)$ \\
\hline Married & $21(10.1)$ \\
\hline Separated/divorced & $4(1.9)$ \\
\hline \multicolumn{2}{|l|}{ Residential areas $(n=209)$ : } \\
\hline Informal settlements & $102(48.8)$ \\
\hline Farms & $4(1.9)$ \\
\hline Suburbs & $14(6.7)$ \\
\hline Inner city & $12(5.7)$ \\
\hline Township/rural & 77 (36.8) \\
\hline
\end{tabular}

The time interval between the DSP event and arrival at the emergency department was available for 127 patients. Almost $80 \%$ of those $(n=100)$ arrived within 9 hours of the event: $0-3$ hours
Table 2: Main type of drug or poison ingested during the deliberate self-poisoning attempt

\begin{tabular}{lc}
\hline Substance & $\boldsymbol{n}(\%)$ \\
\hline Paracetamol & $46(21.7)$ \\
\hline Household chemicals & $41(19.3)$ \\
Antiretroviral medicine & $21(9.9)$ \\
Antidepressants & $20(9.4)$ \\
\hline Benzodiazepines & $12(5.7)$ \\
\hline Organophosphates & $10(4.7)$ \\
Antibiotics & $9(4.2)$ \\
Antiepileptic medicine & $8(3.8)$ \\
Antihypertensive medicine & $7(3.3)$ \\
Other & $38(17.9)$ \\
\hline
\end{tabular}

(48.8\%, $n=62)$, 4-6 hours $(20.5 \%, n=26)$ and $7-9$ hours $(9.5 \%$, $n=12)$.

Medical co-morbidities recorded included hypertension (1.4\%, $n$ $=3)$, depression (9.4\%, $n=20)$, epilepsy $(2.8 \%, n=6)$ and HIV infection $(9.0 \%, n=19)$. Of the 140 female patients, $10.7 \%(n=$ 15) were pregnant.

\section{Substances ingested}

Table 2 summarises the main type of drugs and poison ingested by the DSP patients. The highest percentage of patients took paracetamol $(21.7 \%, n=46)$ while $19.3 \%(n=41)$ ingested household chemicals and $9.9 \%(n=21)$ antiretroviral (ARV) medication. More than one substance was ingested in $40.1 \%$ $(n=85)$ of the DSP cases: two substances by $25 \% \quad(n=53)$, three substances by $11.3 \%(n=24)$ and more than three substances by $3.8 \%(n=8)$.

Household chemicals included paraffin, hair relaxer, furniture polish, after-shave, bleach, brake fluid, turpentine, nail polish remover, toilet detergents and dishwashing liquid. Drugs and poison listed under 'Other' $(17.9 \%, n=38)$ included iron tablets, multivitamins, laxatives, rat poison (containing warfarin), oral hypoglycaemic agents, eardrops, metoclopramide, aspirin, simvastatin, actraphane injection, prednisolone, isoniazid and sucralfate.

Alcohol co-ingestion was reported for 28 patients (13.2\%). A toxicology screening was done for $50.9 \%(n=108)$ of the

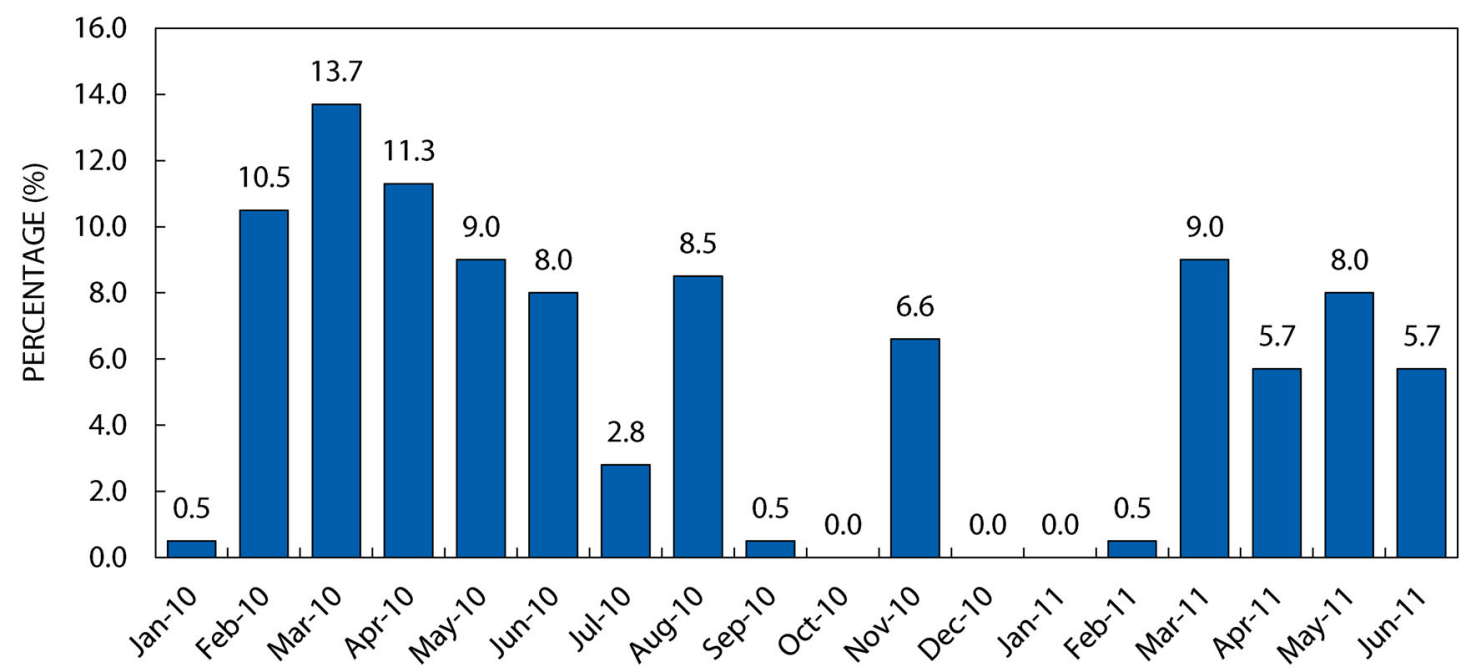

Figure 1: Percentage of patients presenting at the emergency department for treatment of deliberate self-poisoning during the study period ( $n=212$ ). 
patients. Of these patients, three (2.8\%) tested positive for cannabis and four (3.7\%) for opiates.

Seventy-five patients $(35.4 \%)$ took their own medication while $17(8.0 \%)$ took relatives' medication. Information on access to the drugs or poison was not available for $70(33.0 \%)$ patients and not stated for nine (4.2\%) patients.

\section{Reasons for deliberate self-poisoning}

Table 3 summarises the main reasons for the DSP. Only 81 (38.2\%) of the 212 patient files had this information captured. Half of the patients had troubled relationships, of whom $39.5 \%$ $(n=32)$ were unmarried and $9.9 \%(n=8)$ were married. Family issues comprised mainly conflict with parents and grandparents. Medical reasons included HIV infection, cancer and dental problems. The psychosocial issues of the 10 patients were not specified in their clinical notes.

\section{Clinical state on presentation}

Of the 197 patients with documented Glasgow Coma Scale ${ }^{16}$ (GCS), $88.8 \%(n=175)$ had a normal GCS score of 15 (i.e. nonaltered mental status) while $11.2 \%(n=22)$ had abnormal GCS scores of $<15$ (i.e. altered mental status). Of the abnormal GCS group, 5.6\% $(n=11)$ had scores between 13 and 14 (i.e. mild altered mental status), 3\% $(n=6)$ had scores between 9 and 12 (i.e. moderate altered mental status) while $2.5 \%(n=5)$ had a score of $\leq 8$ (i.e. severe altered mental status).

For most of the patients, results for blood pressure $(n=209)$, pulse $(n=208)$ and oxygen saturation $(n=200)$ were recorded. On presentation at the emergency department, patients mostly had normal blood pressure $(69.9 \%, n=146)$, pulse (66.8\%, $n=139)$ and oxygen saturation $(95.5 \%, n=191)$. Respiratory rate and temperature results were recorded for only 137 and 161 patients, respectively. The available results showed that $83.9 \%(n=115)$ of patients had a normal respiratory rate and $86.3 \%(n=139)$ had a normal temperature.

\section{Patient outcomes}

The outcome of 204 patients was available in their clinical notes. Two patients $(1.0 \%)$ died; one ingested potassium permanganate while the other one overdosed on an antipsychotic agent. A total of 127 patients (62.3\%) were discharged directly from the emergency department. Sixty-five patients (31.9\%) were admitted to the medical ward while five $(2.5 \%)$ were admitted to the intensive care unit (ICU). Three $(1.5 \%)$ patients were admitted to the gynaecology ward and two $(1.0 \%)$ patients to the surgical ward. Most of the 204 patients $(81.4 \%, n=166)$ were referred for psychological evaluation.

Table 3: Main reasons for deliberate self-poisoning $(n=81)$

\begin{tabular}{lc}
\hline Reason & $\boldsymbol{n}(\%)$ \\
\hline Relationship issues (unmarried) & $32(39.5)$ \\
\hline Family issues & $15(18.5)$ \\
Psychosocial issues & $10(12.3)$ \\
Marital issues & $8(9.9)$ \\
Depression & $7(8.6)$ \\
Medical reasons & $5(6.2)$ \\
Unemployment & $2(2.5)$ \\
\hline Post-traumatic stress disorder & $2(2.5)$ \\
\hline
\end{tabular}

\section{Discussion}

The high incidence of DSP among females, as shown in this study, is similar to studies done internationally ${ }^{15,17-19}$ and nationally. ${ }^{5,12}$ Women are more prone to DSP while men generally attempt suicide by means of more violent methods, such as hanging or self-inflicted gunshot. ${ }^{5}$ Successful suicide may be the reason why men are underrepresented in DSP statistics.

The age group of 20-29 years accounts for the highest frequency of DSP (44.8\%). This result differs from a Unites States (US) study where the rate was found to be higher in the age group 15-19 years. ${ }^{17}$ However, similar results were found in the United Kingdom (UK), ${ }^{15}$ where the majority of DSP patients were younger than 30 years, and in $\operatorname{Oman}^{18}$ and India ${ }^{20}$ where DSP occurred in the age group 20-30 years.

This study showed that the majority of the DSP patients presenting at Pelonomi Regional Hospital emergency department are black. In general, the Indian and Asian population in the Free State is in the minority. ${ }^{21}$ This might explain why they are not represented in this study.

The employment rate for this study population was $65.6 \%$, which is similar to rates reported in studies done in Bloemfontein $(60.0 \%)^{2}$ and Paarl $(53.7 \%){ }^{12}$ There is therefore a strong link between unemployment and suicidal behaviours. Almost $20 \%$ of the DSP patients were learners or students. This may be due to certain problems and stressors specific to this group, e.g. unwanted pregnancies, academic stress, etc. Bajracharya et al. reported similar findings where a higher incidence of deliberate self-harm was found among students and the unemployed. ${ }^{20}$ In the Bloemfontein study, students comprised $30 \%$ of patients with suicidal behaviour.

Most of the DSP patients were single and unmarried (88.0\%). This might be a reflection of cultural marital practices among a certain group of black South Africans where traditional marriage is the norm. ${ }^{22}$

Over $80 \%$ of DSP attempts occurred among patients residing in areas of low socioeconomic status. An assessment of poverty, unemployment and inequality in the Free State showed poverty to be a rural phenomenon. ${ }^{23}$ Similar results were found in the Western Cape where the highest number of overdose cases per square kilometre occurred in an informal settlement with a high density of people and very poor socioeconomic circumstances. ${ }^{12}$

The highest percentages of patients presented with DSP between February 2010 and April 2010. Stark et al. ${ }^{2}$ reported that the majority of suicide cases occurred during the first four months of the year. People generally tend to overspend during the end-of-year holiday and festive period, such that they find it difficult to manage their usual monthly expenses during the first months of the new year. In addition, this period marks the beginning of a new academic session for learners and students who might also be returning from home. Lack of coping strategies for academic hurdles, coupled with possible financial and psychosocial stressors, may trigger DSP ideation for attention seeking. For the months of October 2010, December 2010 and January 2011 there were no records of patients presenting with DSP. From this unequal distribution of cases, the authors cannot speculate on the possible reasons, as it cannot be verified whether there were definitely no DSP cases during these 
months, or whether there were cases, but the patients' files were missing or lost.

\section{Substances ingested during DSP attempt}

Paracetamol, one of the most common over-the-counter medications, was the drug with the highest percentage of use (21.7\%) for DSP in this study. This may be because paracetamol is readily available and used in most homes for the treatment of minor pains/aches and fever. A study done in the UK ${ }^{24}$ on DSP showed that paracetamol and paracetamol-containing compounds were implicated in about $50 \%$ of the cases while $41 \%$ of DSP patients ingested paracetamol and non-steroidal antiinflammatory drugs in the Oman study. ${ }^{18}$

About $10 \%$ of the patients used ARVs for their DSP attempt. As of 2012, approximately 1.4 million South Africans were on ARV treatment, and 2205 centres were capable of dispensing ARVs. ${ }^{25}$ The widespread availability of ARVs for patients with HIV infection, coupled with their high tendency for depression, ${ }^{26}$ might explain the reason for the use of ARVs for DSP.

The widespread use of antidepressants (9.4\%) for DSP may imply a high prevalence of depression among these patients, since they are prescription drugs. This can be substantiated by the fact that the highest percentage of the patients overdosed on their own medication. However, it is acknowledged that these patients might have also used medication belonging to relatives, friends or someone else. A high rate of the use of antidepressants for DSP (20\%) in the UK was found to correlate with an increase in the rate of their prescription. ${ }^{24}$

Household chemicals are readily available with few or no restrictions on their purchase. In this study, $19.3 \%$ of the patients ingested household chemicals. This differs from findings in the UK where non-ingestible chemicals such as bleach and disinfectants were ingested by only about $1 \%$ of the patients. ${ }^{24}$

About $40 \%$ of the patients ingested multiple substances. This is in line with results from the Western Cape study where $42.3 \%$ of the patients overdosed on more than one drug. ${ }^{12}$ In comparison, $62.9 \%$ of patients in the $\mathrm{UK}^{24}$ and $18.7 \%$ in Oman $^{18}$ ingested substances from different classes of drugs.

Alcohol co-ingestion was reported in $13.2 \%$ of the DSP cases. A similar British study showed a higher incidence of alcohol coingestion of $29 \%$. $^{27}$

\section{Main reasons for DSP}

Marital and relationship problems resulted from misunderstanding, infidelity, unwanted pregnancies, sexual dissatisfaction, financial constraints, relationship breakdown, divorce or separation and the associated court verdict on the custody of children. Family issues included conflict with close relatives, mostly arising from disapproval of a boyfriend or girlfriend.

The inability to cope with the reality of some chronic and terminal medical conditions, such as hypertension, diabetes mellitus, HIV infection and cancer, might have attributed to suicidal ideation. In addition, the burden accompanying these medical conditions such as pain and side effects of treatment may be overwhelming and unbearable to some patients. For two patients, post-traumatic stress disorder because of rape was listed as reason for the DSP attempt.
In all, these findings are similar to the results of the studies done in Australia, ${ }^{28}$ Oman $^{18}$ and Bloemfontein. ${ }^{5}$

\section{Clinical presentation and outcome}

The majority of the patients were fully conscious and coherent when assessed at the emergency department. Attention seeking rather than suicidal intent is therefore a high possibility here. The low GCS observed in some of the DSP cases might be because of delayed arrival at the emergency department; however, this cannot be confirmed as the information on time intervals between the attempt and presentation was missing in the majority of files. The choice of substance might also have determined the GCS; central nervous system drugs, such as antiepileptic and antidepressant medication, may result in depressed levels of consciousness. Patients with underlying medical co-morbidities may already have a compromised organ system, and a tendency to deteriorate faster is therefore possible.

About $60 \%(n=127)$ of the patients in this study were discharged without complications. This may be because almost half of these patients $(48.0 \%, n=61)$ presented at the emergency department within nine hours. Also, 90.6\% $(n=115)$ were younger than 40 years and $66.1 \%(n=84)$ were without medical co-morbidities. These factors are in favour of functional, non-deteriorating organ system and good response to resuscitation, thereby increasing the chance of a favourable outcome. In addition, this may further corroborate the fact that these patients engaged in DSP in order to seek attention from close relatives or loved ones.

Alcohol co-ingestion did not have a significant effect on discharge. Therefore, alcohol co-ingestion has not been associated with worse outcome of DSP cases in this study.

A third (31.9\%) of the DSP patients were admitted to different medical wards at Pelonomi Regional Hospital. This is in keeping with a study done in the UK where about $20 \%$ of the workload of the medical department was due to cases of selfpoisoning. ${ }^{29}$ There is therefore a great need for better fortification and equipping of the medical wards in order to meet this demand.

Two patients died after their DSP attempt. Both were black females in their thirties, unemployed and single, with no indication of alcohol consumption. One patient was HIV-positive and ingested half a bottle of potassium permanganate. Even though she arrived at the emergency department within three hours after the attempt, she died nine hours later. The second patient overdosed on an antipsychotic. She was admitted to the medical ward, but died after 24 hours. Underlying medical conditions and the potency of the drugs or poison used might be important determinants of the clinical outcome of DSP.

The majority of the patients were referred to the hospital's psychologist for evaluation, which is in line with the existing hospital policy at Pelonomi Regional Hospital regarding the management of DSP cases.

\section{Study limitations}

The study focused on only one regional hospital in the Free State. Therefore, the results may not necessarily reflect those of other regional hospitals in South Africa. 
Some records were misplaced or lost and therefore excluded from the study. For example, no data were available for the months of October 2010, December 2010 and January 2011. This might have significantly influenced the results of this study. Furthermore, incomplete patient history-particularly the reason for DSP - taken by the attending medical doctor has rendered some DSP case files unsuitable for inclusion.

During the patient file reviews, the first author identified and grouped the main drug or poison taken. For patients who ingested multiple substances, apart from the main substance, only the total number was noted on the data form. As a result, there are insufficient data available on the additional substances ingested. The dosages of the substances ingested were not recorded, which could have given credibility to the motive for the DSP attempt

\section{Conclusion}

This study showed that DSP mostly occurred among females in the age group 20-29 years. Most of the patients resided in areas with poor socioeconomic status, and faced relationship, marital, employment and other psycho-socioeconomic problems. These usual stressors trigger suicidal ideation.

The most common drug used for DSP was paracetamol, which is an over-the-counter medication. Other drugs used for DSP were patients' prescribed medication, such as antidepressants and ARVs. In addition, household chemicals were employed for DSP. Little, therefore, can be done to curtail the accessibility of these drugs and poisons.

\section{Recommendation}

Prevention of DSP may be achieved through psychosocial support by community counsellors, social workers and psychologists to the age group mostly affected. Focus areas should include schools, hospitals, places of employment and homes, especially those situated in areas associated with poor socioeconomic status.

Doctors and other health professionals should pay more attention to the psychosocial part of history-taking, as vulnerable patients can be identified easily and referred for psychological assistance in a timely manner.

Caution should be taken by pharmacists and doctors when prescribing medication, especially medication commonly used for DSP.

Proper training of paramedics, emergency department doctors and other relevant health professionals in the management of poisoning is of utmost importance. An adequate supply in emergency departments and other relevant departments of antidotes and other equipment required for the management of poisoning has also become necessary.

Finally, much important information is not captured in the patients' case notes. It is therefore suggested that a document or data form containing the necessary information appropriate for a case of DSP be drawn up. This may be used in the emergency department when assessing these patients.

Acknowledgements - The authors would like to thank the Management of Pelonomi Regional Hospital for approving the study and Ms T Mulder, medical editor, School of Medicine,
UFS, for the technical and editorial preparation of the manuscript.

Disclosure statement - No potential conflict of interest was reported by the authors.

Funding sources - None.

\section{ORCID}

MOA Benedict (ID http://orcid.org/0000-0002-5983-7919

WJ Steinberg (D) http://orcid.org/0000-0001-9944-1807

\section{References}

1. Du Preez J, Steyn F, Booyens K. Risk factors and circumstances surrounding suicide in correctional centres in Gauteng, South Africa. Acta Criminologica S Afr J Criminol. 2015;2(special edition):125-43.

2. Stark K, Joubert $G$, Struwig $M$, et al. Suicide cases investigated the state mortuary in Bloemfontein, 2003-2007. S Afr Fam Pract. 2010;52 (4):332-5. https://doi.org/10.1080/20786204.2010.10874001

3. Malangu N, Ogunbanjo GA. A profile of acute poisoning at selected hospitals in South Africa. South Afr J Epidemiol Infect. 2009;24 (2):14-6. https://doi.org/10.1080/10158782.2009.11441343

4. Camidge DR, Wood RJ, Bateman DN. The epidemiology of self-poisoning in the UK. Br J Clin Pharmacol. 2003;56(6):613-9.

5. du Toit EH, Kruger JM, Swiegers SM, et al. The profile analysis of attempted-suicide patients referred to Pelonomi Hospital for psychological evaluation and treatment from 1 May 2005 to 30 April 2006. S Afr J Psychiatr. 2008;14(1):20-6. https://doi.org/10. 4102/sajpsychiatry.v14i1.40

6. World Health Organization. Preventing suicide. A Resource for nonfatal suicidal behaviour case registration [internet]. c2014 [cited 2018 Sep 12]. Geneva, Switzerland: WHO. Available from: apps.who.int/iris/bitstream/10665/112852/1/9789241506717_eng.pdf

7. Eddleston M, Phillips MR. Self poisoning with pesticides. $\mathrm{Br}$ Med J. 2004;328(7430):42-4. https://doi.org/10.1136/bmj.328.7430.42

8. Fathelrahman Al, Ab Rahman AF, Mohd Zain Z. Self-poisoning by drugs and chemicals: variations in demographics, associated factors and final outcomes. Gen Hosp Psychiatry. 2008;30(5):46770. https://doi.org/10.1016/j.genhosppsych.2008.04.004

9. Senarathna L, Adams J, De Silva D, et al. Personal and professiona challenges in the management of deliberate self-poisoning patients in rural Sri Lanka: a qualitative study of rural hospital doctors' experiences and perceptions. BMC Public Health. 2008;8:373-9. https://doi. org/10.1186/1471-2458-8-373

10. Malangu N. Acute poisoning at two hospitals in Kampala-Uganda. J Forensic Leg Med. 2008;15(8):489-92. https://doi.org/10.1016/j.jflm. 2008.04.003

11. Gunnell D, Eddleston M, Phillips MR, et al. The global distribution of fatal pesticide self-poisoning: systematic review. BMC Public Health. 2007;7:357-71. https://doi.org/10.1186/1471-2458-7-357

12. Laubscher $C$, van Rooyen EEM. The profile of the overdose patient presenting at Paarl Hospital emergency department. S Afr Fam Pract. 2007;49(2):16-16e. https://doi.org/10.1080/20786204.2007.10873510

13. Ani JO, Ross AJ, Campbell LM. A review of patients presenting to accident and emergency department with deliberate self-harm, KwaZulu-Natal, South Africa. Afr J Prim Health Care Fam Med. 2017;9(1):e1-e7. https://doi.org/10.4102/phcfm.v9i1.1234

14. Kapur N, House A, Dodgson K, et al. Management and cost of deliberate self-poisoning in the general hospital: a multi-centre study. J Ment Health. 2002;11(2):223-30. https://doi.org/10.1080/1-0963823 0020023606

15. Prescott K, Stratton R, Freyer A, et al. Detailed analyses of self-poisoning episodes presenting to a large regional teaching hospital in the UK. Br J Clin Pharmacol. 2009;68(2):260-8. https://doi.org/10.1111/j. 1365-2125.2009.03458.x

16. Durant E, Sporer KA. Characteristics of patients with an abnormal Glasgow coma scale score in the prehospital setting. West J Emerg Med. 2011;12(1):30-6. 
17. Prosser JM, Perrone J, Pines JM. The epidemiology of intentional nonfatal self-harm poisoning in the United States: 2001-2004. J Med Toxicol. 2007;3(1):20-4.

18. Zaidan ZAJ, Burke DT, Dorvlo AS, et al. Deliberate self-poisoning in Oman. Trop Med Int Health. 2002;7(6):549-56.

19. Waddy S. Management of the poisoned patient. Anaesth Intensive Care Med. 2007;8(11):474-6. https://doi.org/10.1016/j.mpaic.2007. 08.020

20. Bajracharya MR, Manandha K, Deo KK, et al. Age and gender distribution in deliberate self-poisoning cases. Postgrad Med J NAMS. 2008;8(1):1-4.

21. Frith A. Census 2001. Bloemfontein [Internet]. c2012 [cited 2012 Apr 18]. Available from: http://census.adrianfrith.com/place/40502

22. Hosegood V, McGrath N, Moultrie T. Dispensing with marriage: marital and partnership trends in rural KwaZulu-Natal, South Africa 2000-2006. Demogr Res. 2009;20:279-312. https://doi.org/10.4054/ DemRes.2009.20.13

23. Punt C, Pauw K, Van Schoor M, et al. A profile of the Free State province: demographics, poverty, inequality and unemployment. Provide Project Backgr Pap. 2005;1(4):1-20.

24. Townsend E, Hawton K, Harris L, et al. Substances used in deliberate self-poisoning 1985-1997: trends and associations with age, gender, repetition and suicide intent. Soc Psychiatry Psychiatr Epidemiol. 2001;36(5):228-34.

25. Brand South Africa. HIV: nearly $12 \mathrm{M}$ South Africans tested [Internet] Johannesburg, South Africa: Brand South Africa. c2011 [cited 2018 May 29]. Available from: https://www.brandsouthafrica.com/ governance/health-services/hivtesting-010611

26. Ngum PA, Fon PN, Ngu RC, et al. Depression among HIV/AIDS patients on highly active antiretroviral therapy in the southwest regional hospitals of Cameroon: across-sectional study. Neurol Ther. 2017;6(1):103-14. https://doi.org/10.1007/s40120-0170065-9

27. Owens DW, Jones SJ. The accident and emergency department management of deliberate self-poisoning. $\mathrm{Br} J$ Psychiatry. 1988;152:830-3.

28. Clover K, Carter GL, Whyte IM. Posttraumatic stress disorder among deliberate self-poisoning patients. J Trauma Stress. 2004;17 (6):509-17.

29. Jones AL, Volans $G$. Recent advances: management of self poisoning. Br Med J. 1999;319(7222):1414-7.

Received: 19-06-2018 Accepted: 18-09-2018 